hoped that aerological stations will be set up in sufficient numbers along these meridians to enable good cross-sections to be drawn.

As regards publication of meteorological data for the year, the World Meteorological Organization has taken the bold step of deciding to use microcards. National meteorological services are to be asked to send a copy of the observational records of their stations to the secretariat, where they will be printed on microcards and sold. A trial of the method is to be held in January 1957.

\section{THE PHYSICAL SOCIETY ANNUAL REPORT FOR 1955}

A $T$ the annual general meeting of the Physical Society, held in London at the offices of the Society on May 24, the reports of the council and of the honorary treasurer and the accounts and balance sheet for 1955 were presented and adopted, and the officers and council for 1956-57 were elected. The council reported that the balance of income over expenditure for the year under review was $£ 1,220$. However, it should be noted that expenditure for 1955 was more than $£ 9,000$ greater than for 1954 , $£ 4,000$ of this increase being due to the greater expense of housing the thirty-ninth annual exhibition of scientific instruments and apparatus in the New Hall of the Horticultural Society instead of in the Imperial College of Science and Technology, London, where former exhibitions were held. Interest in the exhibition was as great as ever, the attendance exceeding eighteen thousand, and the increased expenditure on the exhibition was more than balanced by a gain in receipts from exhibitors.

The activities of the Society during the year included five science meetings in London; three joint colloquia with the Institute of Physics on electron physics in London; a three-day meeting at the Atomic Energy Research Establishment, Harwell, during March 31-April 2; and two-day meetings at the Universities of Liverpool and Cambridge during July 5-6 and December 13-14, respectively. A highly successful innovation was a Fellow's luncheon, which was held in London on April 25, the opening day of the annual exhibition. The eighteenth Thomas Young Oration was delivered by Dr. W. S. Stiles, who spoke on the basic data of colour matching and some related aspects of visual theory, and the thirty-ninth Guthrie Lecture by Prof. E. C. Stoner on magnetism in retrospect and prospect ${ }_{t}$; both these lectures have been published in the "Year Book of the Physical Society, 1955". Dr. N. Kurti was the recipient of the tenth Holweck Medal of the Société Française de Physique and the Holweck Prize of the Physical Society; the presentation took place in Paris on May 26, when Dr. Kurti delivered the Holweck Discourse entitled "Le domaine des températures où regnent les spins" (J. Phys. et le Rad., 17, 85; Feb. 1956). The thirty-second Duddell Medal was presented to Dr. R. Kompfner, who gave an address on travelling-wave tubes, and the eleventh Charles Vernon Boys Prize to Dr. J. W. Mitchell, who spoke on some of his work on photographic emulsions.

The Society continues to be represented on various committees and institutions, details of which are listed in the annual report, together with brief accounts of the activities of the four Groups of the Society-the
Colour, Optical, Low Temperature and Acoustics Groups. The summer meetings of the Colour and Optical Groups were held at the Paint Research Station, Teddington, and University College, London, respectively, while the Low Temperature Group for its summer meeting paid a visit to the British Oxygen Company's air separation plant at Brinsworth, to the United Coke and Chemicals Company's hydrocarbon separation plant at Handsworth and to the Low Temperature Physics Laboratory at the University of Leeds.

In the section of the report dealing with publications, it is stated that, after a three years trial, the reprints scheme, whereby members and subscribers of the Society were able to purchase reprints of the papers published in the Society's Proceedings, has had to be discontinued. The general demand for the scheme was far too small to justify the large expense involved. Two conference reports, "Defects in Crystalline Solids", the report of a conference held in Bristol during 1954, and "The Physics of the Ionosphere", the report of a conference held in Cambridge during 1954, which were mentioned in the 1954 annual report, were published during 1955, and Volume 18 of "Reports on Progress in Physics", containing ten specialist articles, was issued in September. The flow of papers to the Proceedings increased during 1955. 265 papers and 115 research notes and letters to the editor were accepted for publication, as compared with 215 and 111 respectively in the previous year. Seventy-three manuscripts were either rejected or withdrawn. A new annual publication, commenced in the autumn of 1955, was "The Year Book of the Physical Society", containing the texts of the presidential address, the Guthrie Lecture and other special lectures to the Society, in addition to the annual report and accounts.

The officers and council of the Society for 1956-57 are as follows: President, Prof. N. F. Mott; Vice. Presidents (in addition to those who have filled the office of president), Dr. A. B. Wood, Prof. S. Devons, Prof. F. Llewellyn Jones and Prof. H. Jones; Honorary Secretaries, Dr. C. G. Wynne and Dr. H. H. Hop. kins ; Honorary Foreign Secretary, Prof. E. N. da C. Andrade; Honorary Treasurer, Mr. A. J. Philpot; Honorary Librarian, Dr. R. W. B. Pearse; New Ordinary Members of Council, Dr. V. E. Cosslett, Dr. D. Gabor and Mr. E. S. Shire.

\section{THE DELI PALM}

A RECENT issue of the Journal of the West African Institute for Oil Palm Research (No. 3, pp. $5-87 ; 1955)$ contains a number of articles of interest both to botanists and planters. It is an odd and sometimes disconcerting fact that a haze of obscurity overhangs the origin of so many of our major crops. This is particularly true of the Deli palm - a strain of Elaeis guineensis that has been cultivated with great success in the East concerning which an important article is contributed by A. F. M. Broekmans and F. W. Toovey. Seed of the Deli palm was introduced into Nigeria at various times before the Second World War in the hope that it would afford a means both of increasing the yield of palm oil and of resisting some of the diseases to which the local West African oil palm is subject. It is reported that, over the first eight-year period, the local strains gave a much higher yield of fruit bunches than the Deli strains; 